\title{
Processo de auditoria e faturamento de contas em hospital geral privado: um estudo de caso
}

\author{
Raquel Silva Bicalho Zunta ${ }^{1}$, Antônio Fernandes Costa Lima ${ }^{2}$
}

\footnotetext{
${ }^{1}$ Enfermeira, Doutora em Enfermagem. Docente da Universidade Paulista. São Paulo, SP, Brasil. E-mail: rsbzunta@gmail.com.

${ }^{2}$ Enfermeiro, Doutor em Enfermagem. Professor Doutor da Escola de Enfermagem da Universidade de São Paulo. São Paulo, SP, Brasil. E-mail: tonifer@usp.br.
}

Recebido: 23/10/2016

Aceito: $31 / 08 / 2017$.

Publicado: 01/12/2017.

Como citar esse artigo:

Zunta RSB, Lima AFC. Processo de auditoria e faturamento de contas em hospital geral privado: um estudo de caso. Rev. Eletr. Enf [Internet]. 2017 [acesso em:

____19:a43. Disponível em: http://dx.doi.org/10.5216/ree.v19.42082.

\section{RESUMO}

Mapear, descrever e validar o processo de auditoria e faturamento de contas e recursos de glosas em um hospital geral, de grande porte, privado, foi o objetivo deste estudo. Pesquisa exploratória, descritiva, do tipo estudo de caso. Foram realizados momentos de observação não participante nos Setores de Auditoria Interna e de Recurso de Glosas do hospital visando o mapeamento dos processos objeto de estudo. Os dados obtidos foram validados por especialistas da área de auditoria de contas hospitalares, internos e externos ao hospital. Os processos, descritos e ilustrados na forma de três Fluxogramas, favorecem aos profissionais racionalizar as atividades e o tempo despendido no faturamento hospitalar evitando/minimizando a ocorrência de falhas e gerando resultados financeiros mais eficazes. 0 mapeamento, a descrição e a validação dos processos de auditoria e faturamento e recurso de glosas propiciaram maior visibilidade e legitimidade às ações desenvolvidas pelos enfermeiros auditores.

Descritores: Faturamento; Documentação; Auditoria de Enfermagem; Estudos de Casos.

\section{INTRODUÇÃO}

Frente às crises internacionais e aos avanços tecnológicos os cenários econômicos e financeiros sofrem constantes mudanças que ocasionam às empresas perda de mercado; diminuição das margens de lucro; aumento da exigência quanto à qualidade dos produtos, da concorrência e do mercado consumidor ${ }^{(1)}$. Nesse ambiente dinâmico, as instituições prestadoras de serviços de saúde, com vistas a manutenção de sua sustentabilidade, precisam desenvolver-se economicamente por meio do gerenciamento eficiente de seus inúmeros processos ${ }^{(2)}$.

Tais instituições, consideradas como empresas complexas, são obrigadas a adaptar-se, 
continuamente, aos cenários político e financeiro, assim como tornar-se flexíveis para incorporarem estratégias capazes de atender ao usuário interno e externo ${ }^{(3)}$. Ressalta-se que, no cenário nacional, as dificuldades crescentes de financiamento do setor saúde e o elevado custo dos serviços têm preocupado aos financiadores, as autoridades, aos prestadores e aos usuários.

O faturamento, na administração financeira hospitalar, constitui-se em um processo que permite aos gestores conhecerem a rentabilidade dos serviços de saúde e gerir seus custos, qualidade e receitas. Por intermédio dele, a prestação de serviços e o consumo de materiais e de medicamentos originarão a conta hospitalar e se transformarão em moeda corrente. Inicia-se quando o paciente é admitido no hospital originando diversos procedimentos de atendimento às suas necessidades de saúde, que devem ser minuciosamente documentados pela equipe multiprofissional em seu prontuário. A captura adequada destes dados gerará a cobrança, em vista disso deve haver fluidez destas informações para facilitar o fechamento da fatura ${ }^{(4)}$.

Nessa perspectiva, a auditoria de contas hospitalares é imprescindível para a comprovação da realização dos procedimentos aos pacientes, por meio da documentação constante em prontuário, pois fornece subsídios para viabilizar a cobrança junto às fontes pagadoras ${ }^{(5)}$.

As instituições hospitalares, públicas e privadas, que prestam serviços às operadoras de planos de saúde (OPS) têm investido na auditoria de contas visando à adequada remuneração do atendimento prestado. A auditoria pode ser realizada por diferentes profissionais, entretanto vem se consolidando, cada vez mais, como uma área de importante atuação dos enfermeiros.

Além de verificar a compatibilidade entre os procedimentos realizados e a cobrança dos itens componentes das contas hospitalares, o enfermeiro auditor tem potencial para atuar de forma educativa na equipe de saúde contribuindo, com seus conhecimentos, para a obtenção de resultados financeiros positivos, evitando a ocorrência de glosas, e preservando relações éticas entre o contratado e o contratante. Para tanto, deve estar informado e constantemente atualizado quanto às mudanças na prática assistencial, sejam elas relativas a medicamentos ou materiais, para que possa abordar os erros/falhas de registros com propriedade e, também, orientar aos colaboradores quanto aos problemas/deficiências encontrados e apontar alternativas corretivas e/ou preventivas ${ }^{(6)}$.

A prática das OPS de glosar itens do faturamento das contas hospitalares, devido falhas nos registros, tem sido impactante para o orçamento das organizações de saúde gerando prejuízos financeiros decorrentes do não recebimento da remuneração adequada pelos serviços prestados ${ }^{(5)}$.

No faturamento, as evasões de receitas operacionais podem estar relacionadas a não cobrança dos materiais e medicamentos utilizados; não cobrança dos serviços de apoio diagnóstico; não cumprimento dos prazos de entrega do faturamento; não recebimento dos serviços prestados ocasionado por glosas e tabelas desatualizadas de procedimentos ${ }^{(4)}$.

Considerando que o adequado faturamento hospitalar está relacionado às ações desenvolvidas durante a auditoria interna, que pode detectar falhas e intervir para que estas não se tornem recorrentes, 
realizou-se o presente estudo objetivando mapear, descrever e validar o processo de auditoria e faturamento de contas e recursos de glosas em um hospital geral, de grande porte, privado.

\section{MÉTODO}

Pesquisa exploratória, descritiva, do tipo estudo de caso único ${ }^{(7)}$, realizada em um Hospital geral, de grande porte, privado, após a aprovação dos Comitês de Ética em Pesquisa da Escola de Enfermagem da Universidade de São Paulo - EEUSP (parecer $n^{\circ} 801.824$ ) e do hospital campo de estudo - HCE (parecer $n^{\circ}$ $822.825)$.

O estudo de caso único possibilita a investigação de um fenômeno contemporâneo, em profundidade, em seu contexto real, representar uma investigação empírica e compreender um método abrangente, com a lógica do planejamento, da coleta e da análise de dados ${ }^{(7)}$.

O HCE, localizado na zona sul da cidade de São Paulo, é certificado pela Organização Nacional de Acreditação - ONA nível 3 e acreditado pela Joint Commition Internacional (JCI). Integra uma rede hospitalar e dispõe de 418 leitos destinados ao atendimento de pacientes particulares e provenientes de operadoras de planos de saúde (OPS), tendo convênio com mais de 60 empresas e planos de assistência médica. Sua infraestrutura compreende unidades de internação de Clínica Médico-Cirúrgica, que atendem variadas especialidades; Maternidade com berçário setorial, contribuindo para o alojamento conjunto e estimulando o processo da amamentação, Pronto Socorro, Centro Cirúrgico, Centro Obstétrico e Unidade de Terapia Intensiva Adulto e Neonatal.

Possui um Setor de Auditoria Interna, que realiza a pré-análise de, em média, 3.000 contas por mês com o intuito de minimizar as perdas financeiras e contribuir com o faturamento Institucional. Para tanto, conta com uma equipe composta por 11 enfermeiras auditoras, uma enfermeira supervisora, oito auxiliares administrativos e um mensageiro/aprendiz.

Com o propósito de aumentar a confiabilidade do estudo de caso e nortear a coleta de dados foi elaborado um protocolo ${ }^{(7)}$ contendo as etapas da pesquisa, o objetivo de cada etapa e as atividades necessárias à sua consecução.

Inicialmente, foram realizadas visitas aos Setores de Auditoria Interna e de Recurso de Glosas visando o mapeamento dos processos de auditoria e faturamento e recurso de glosas por meio de observação não participante.

Os dados obtidos foram documentados descritivamente, ilustrados na forma de três Fluxogramas e validados pela Enfermeira Supervisora do Setor de Auditoria Interna, Enfermeira da Educação Continuada Operacional e Enfermeira Supervisora do Setor de Recurso de Glosas do HCE.

A Enfermeira Supervisora do Setor de Auditoria Interna possuía 10 anos de formada, era pós-graduada em Auditoria de Serviços de Saúde e atuava há sete anos no HCE; a Enfermeira da Educação Continuada Operacional, responsável pela interlocução entre o Setor de Auditoria Interna e a equipe do Centro Cirúrgico, possuía 22 anos de formada, era Mestre em Enfermagem e atuava há mais de seis anos no processo de 
faturamento da Assistência no HCE e a Enfermeira Supervisora do Setor de Recurso de Glosas possuía cinco anos de formada e cinco anos de experiência na área de auditoria, era pós-graduada em Auditoria de Serviços de Saúde, possuía Master Business Administration em gestão empresarial, e estava há três anos no HCE.

Posteriormente, foi realizada uma oficina, na EEUSP, com duração de duas horas, para validação da descrição dos processos mapeados e dos fluxogramas, na qual participaram três enfermeiras especialistas, da área de auditoria de contas hospitalares, externas ao HCE. O tempo de formada destas enfermeiras variou entre 14 e 27 anos, com média de 19 anos (DP= sete anos). Quanto ao tempo de experiência em auditoria de contas hospitalares houve variação de cinco a 26 anos, com tempo médio de 12,66 anos (DP=11,59 anos). As enfermeiras auditoras receberam, previamente, todo o material de análise e todas as suas observações e proposições foram discutidas, em profundidade, durante a condução da oficina, e incorporadas após consenso do grupo.

\section{RESULTADOS}

Os processos de auditoria e faturamento e de recurso de glosas, mapeados e validados, serão apresentados a seguir.

\section{O processo de auditoria e faturamento do HCE}

A Unidade de prestação de serviços de saúde ao paciente é responsável pelo lançamento das informações referentes à sua alta hospitalar no sistema eletrônico Tasy. O prontuário do paciente é organizado e encaminhado ao Serviço de Arquivo Médico e Estatística (SAME) que, por sua vez, o envia ao Setor de Pré-Faturamento.

O Setor da Administração é notificado da alta hospitalar, por intermédio do sistema Tasy, e encaminha o respectivo prontuário financeiro (envelope onde estão contidas todas as guias de solicitação de internação, os documentos administrativos do Hospital e o contrato do paciente) para o Setor de Pré-Faturamento.

No Setor de Pré-Faturamento o prontuário do paciente é confrontado com o prontuário financeiro. Estando todas as documentações corretas, ambos podem ser encaminhados ao Setor de Auditoria Interna, como ocorre com a maioria das OPS, ou subsidiar a emissão de nota fiscal (NF) que será encaminhada diretamente à quatro OPS cujos prontuários não são submetidos à pré-análise por questões contratuais.

$\mathrm{Na}$ ocorrência de alguma pendência em relação aos documentos contidos nos prontuários são realizadas ações distintas: no caso das contas que serão pré-analisadas o prontuário financeiro é retido e o prontuário do paciente encaminhado para o Setor de Auditoria Interna e, em se tratando de OPS cujas contas não serão auditadas internamente, o próprio Setor de Pré-Faturamento assume a responsabilidade de efetuar as adequações necessárias para a emissão da NF.

Depois de ser analisado no Setor de Auditoria Interna o prontuário do paciente é devolvido ao Setor de Pré-Faturamento onde é unificado com o prontuário financeiro. Então, ambos são encaminhados ao Setor de Coordenação de Guias, onde se solicitarão os documentos que estavam faltando do prontuário financeiro. 
Após rigorosa conferência os dois prontuários são novamente encaminhados para o Setor de Auditoria Interna.

A enfermeira auditora, após ter realizado a análise técnica do prontuário do paciente, na etapa anterior, imprime a conta hospitalar para confrontá-los. Caso constate a necessidade efetua os devidos ajustes na conta, via sistema Tasy, imprimindo-a novamente. Então, encaminha o prontuário do paciente, a conta hospitalar e o prontuário financeiro para a auditoria da OPS (auditoria externa).

Quando há conformidade entre a auditoria interna e externa a OPS devolve toda essa documentação ao Setor de Auditoria Interna e, de lá, são encaminhados para o Setor de Faturamento onde se emitirá uma $\mathrm{NF}$, encaminhada à OPS, para a cobrança e faturamento dos serviços prestados.

Sendo detectada a não conformidade no processo de auditoria externa a OPS realiza a negociação com a enfermeira do Setor de Auditoria Interna. Após negociação entre as partes serão realizados os devidos ajustes e a conta hospitalar será encaminhada à OPS e os documentos enviados ao Setor de Faturamento para a emissão da NF, cobrança e faturamento.

No que diz respeito as quatro OPS com contas não auditadas internamente no HCE, após a adequação da documentação pelo Setor de Pré-Faturamento, o Faturamento emite e encaminha um espelho da conta em formato eletrônico, denominado demonstrativo XML, à OPS para a cobrança dos serviços prestados.

Os fluxogramas do processo de auditoria e faturamento e do processo de faturamento das OPS com contas hospitalares não submetidas à pré-análise podem ser visualizados nas Figuras 1 e 2: 


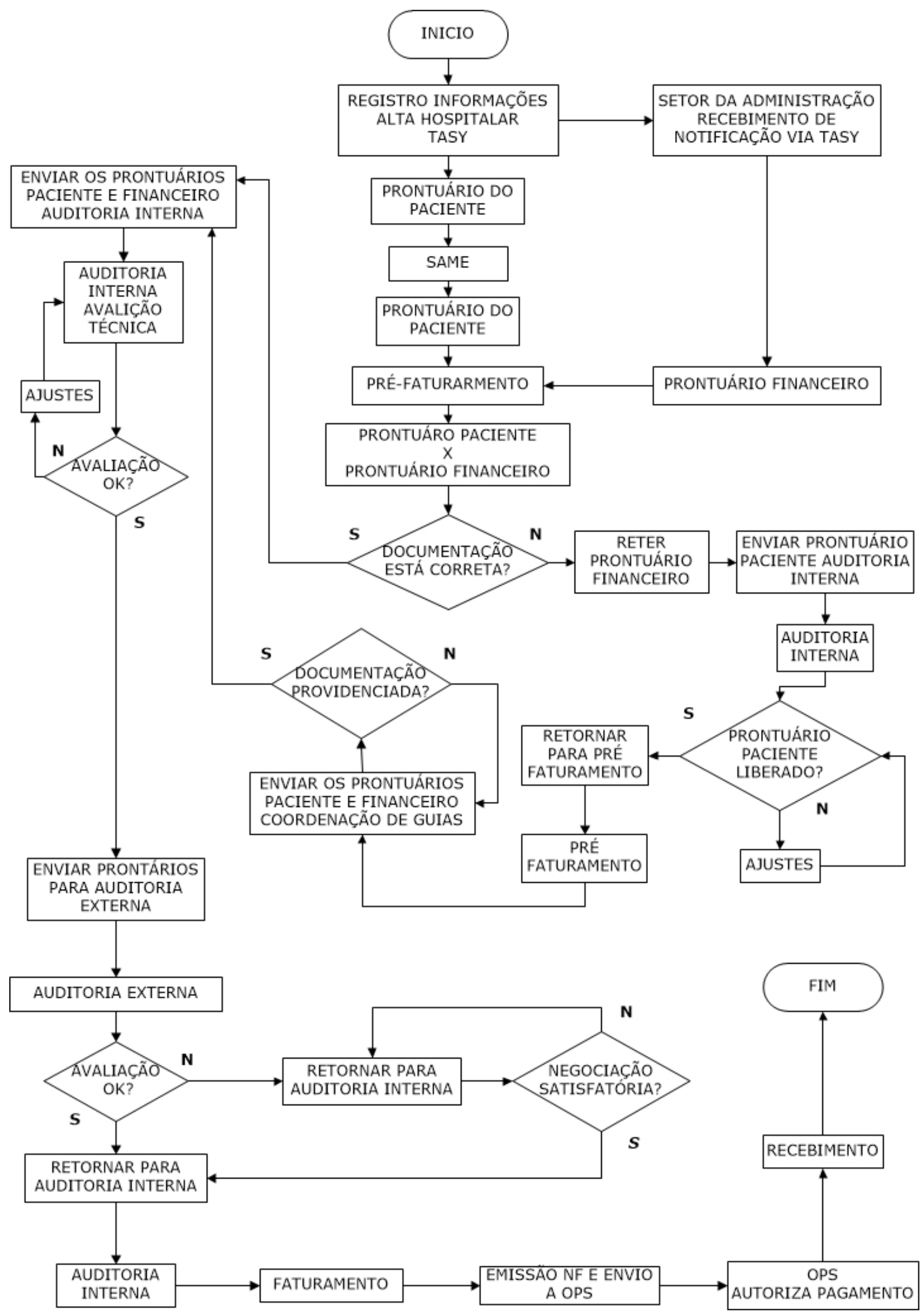

Figura 1: Fluxograma do processo de Auditoria e Faturamento do HCE. São Paulo, SP, Brasil, 2016. 


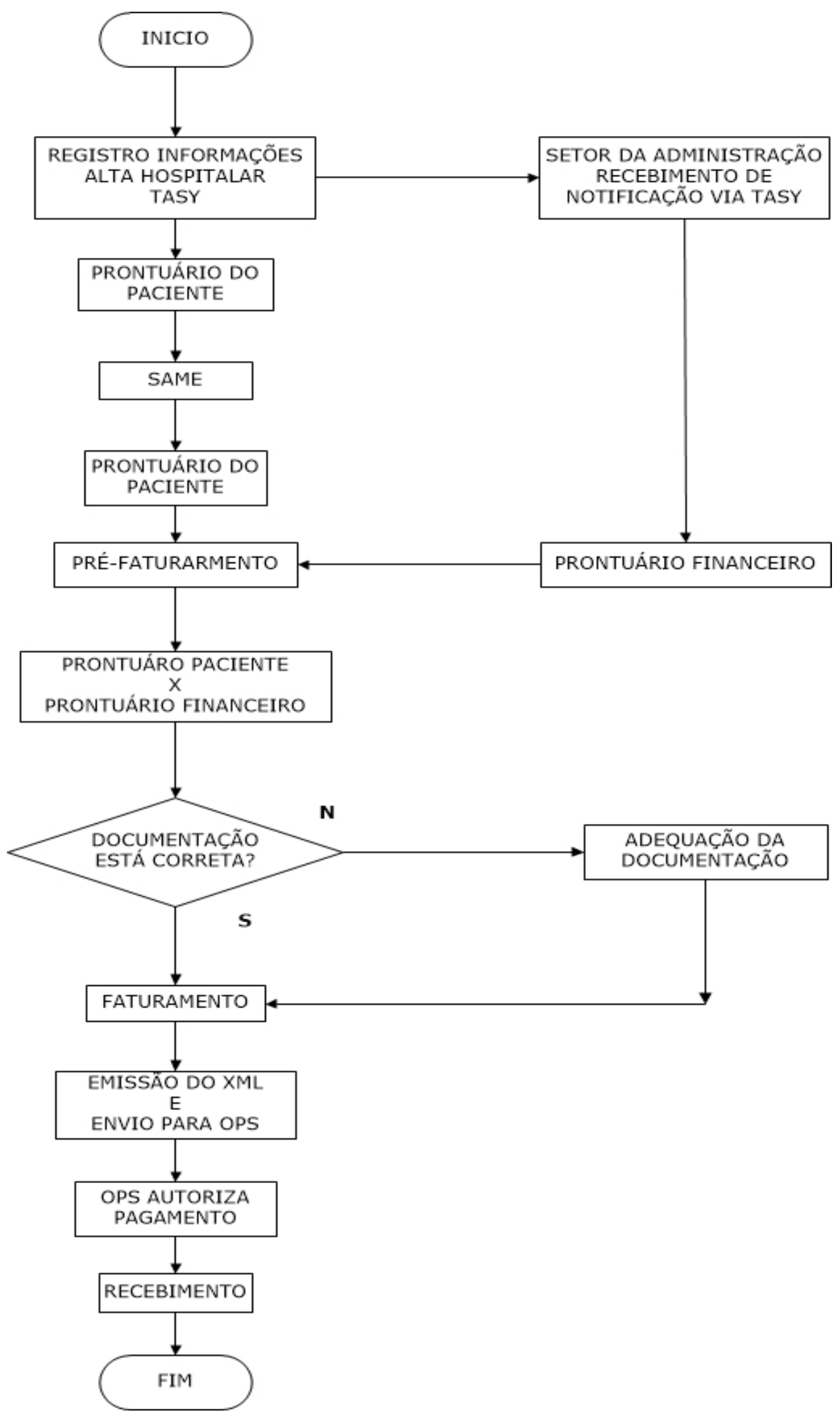

Figura 2: Fluxograma do processo de Faturamento das contas não submetidas à pré- análise no HCE. São Paulo, SP, Brasil, 2016.

O processo de recursos de glosas do HCE

O Setor de Faturamento gera o demonstrativo XML que será encaminhado à OPS. Quando está 
previsto, em contrato, a NF já é encaminhada junto com este demonstrativo. Nestes casos, após análise da OPS, havendo concordância, será efetuado o pagamento. Quando houver discordância será gerado o XML em glosa dos itens considerados indevidos e este demonstrativo será encaminhado ao Setor de Recurso de Glosa (RG). Após análise no RG, havendo concordância entre as partes, poderá ou não ocorrer o recebimento do valor total cobrado. O RG utilizará esta informação para compor o indicador de glosas do HCE, o valor acordado será autorizado pela OPS e ocorrerá o pagamento.

Em relação as quatro OPS com contas não auditadas no HCE, ou seja, sem emissão de NF, o Setor de Faturamento enviará o demonstrativo XML e a documentação pertinente. Estando a OPS de acordo, autorizará o pagamento devolvendo a documentação para o Faturamento, para a emissão de NF e recebimento do valor apresentado. A OPS não concordando gerará o XML em glosa dos itens considerados indevidos e este demonstrativo será encaminhado ao RG, que necessitará realizar a análise técnica do prontuário do paciente, confrontando-o com os dados do demonstrativo, e, se preciso for, poderá solicitar relatórios médicos complementares.

Após essa análise, o RG negociará com a OPS e, havendo concordância entre as partes, o valor acordado, sem a geração de glosas, será encaminhado para o Faturamento para a emissão de NF e ocorrerá o pagamento. Nos casos de discordância, o RG utilizará esta informação para compor o indicador de glosas do HCE, e o valor acordado será autorizado pela OPS e encaminhado ao Faturamento para a emissão de NF e recebimento. Não havendo consenso, entre o RG e a OPS, a negociação será transferida para os responsáveis do Setor de Comercial, de ambas, que darão continuidade as tratativas até o alcance de um acordo.

O fluxograma do processo de Recurso de Glosas do HCE pode ser visualizado na Figura 3: 


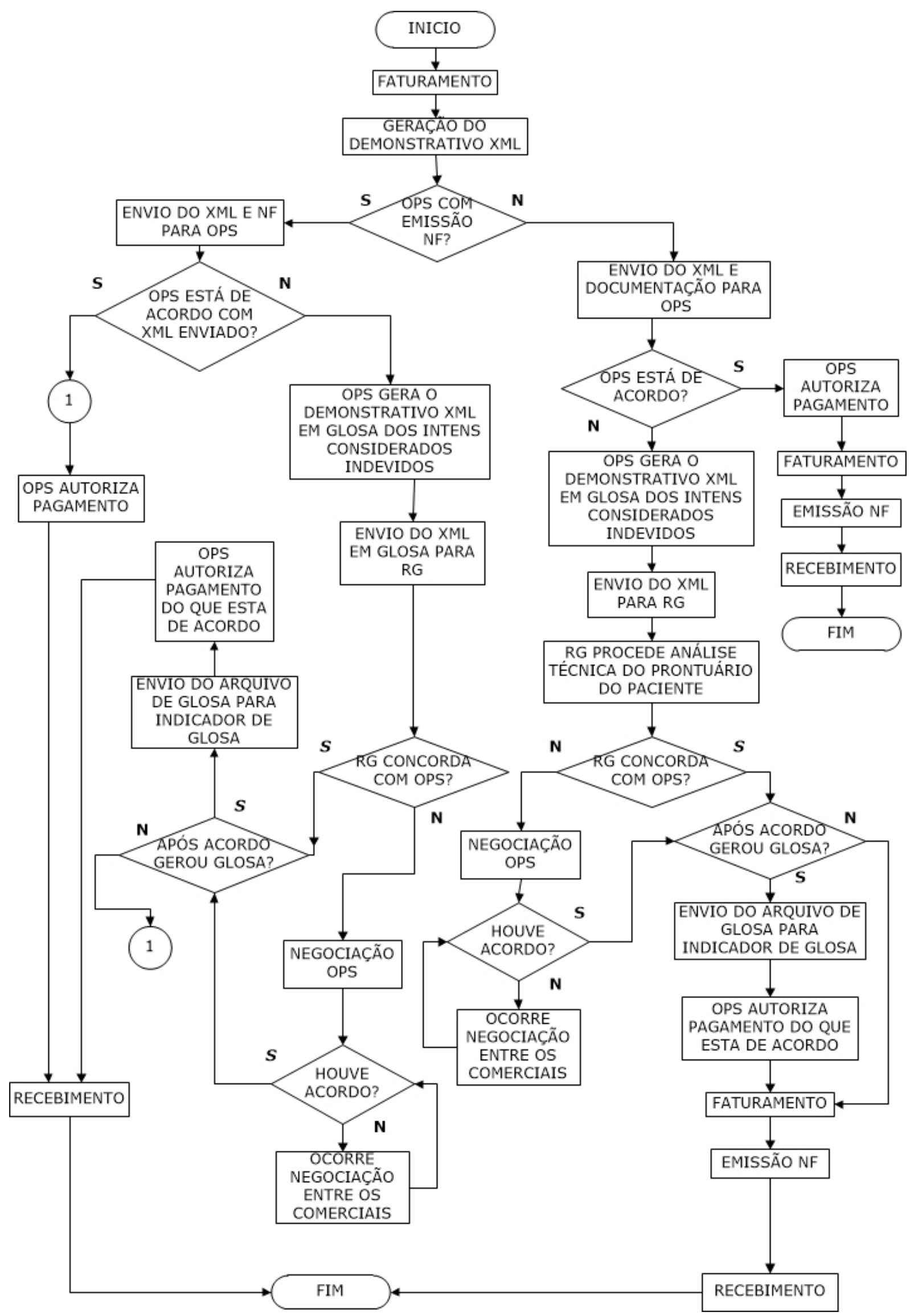

Figura 3: Fluxograma do processo de Recurso de Glosas do HCE. São Paulo, SP, Brasil, 2016.

\section{DISCUSSÃO}

As organizações de saúde, públicas e privadas, que prestam serviços às OPS investem na auditoria de 
contas hospitalares para assegurar a adequada remuneração do atendimento prestado. A auditoria constitui, também, uma importante ferramenta que pode subsidiar ações educativas para a melhoria contínua da documentação nos prontuários, diminuindo as não conformidades entre o registro da assistência prestada ao paciente e os itens cobrados na conta hospitalar evitando o comprometimento do faturamento assistencial ${ }^{(8)}$.

O HCE vem investindo na auditoria de contas hospitalares, há 25 anos, por meio da pré-análise dos prontuários, objetivando minimizar/reduzir as perdas financeiras e, consequentemente, obter um faturamento mais adequado. Para tanto, conta com uma equipe de enfermeiros auditores e de recurso de glosas que tem desenvolvido atividades específicas e complementares nos processos de auditoria e faturamento e de recurso de glosas.

O mapeamento e descrição destes processos, devidamente validados por especialistas com grande experiência na área de auditoria de contas hospitalares, tiveram como propósito contribuir com o HCE na melhoria da gestão, organização e controle das atividades realizadas, bem como inspirar a outras organizações hospitalares a explicitarem as ações desenvolvidas no processo de faturamento com vistas a sua melhoria contínua. Destaca-se que o mapeamento de processos como uma importante ferramenta para o gerenciamento por processos, sendo fundamental sua utilização em qualquer tipo de organização(9).

Além do caráter gerencial, o mapeamento auxilia na melhoria de processos já existentes e/ou facilita a implantação de uma estrutura de gestão voltada a processos. Possui um apelo comunicativo que possibilita visualizar o sequenciamento de atividades e suas interações contribuindo para a gestão da melhoria contínua e desempenho do negócio. A incorporação de melhorias aos processos, norteada pelo mapeamento, propicia o aumento de lucratividade, diminuição de complexidades operacionais, redução de custos, aumento da qualidade, identificação de atividades de baixo valor agregado, identificação de excesso de tarefas repetitivas ou burocracias, aprimoramento na relação entre atividades e processos ${ }^{(10)}$.

Por intermédio do mapeamento, descrição e validação dos processos de auditoria e faturamento e de recurso de glosas, conferiu-se maior visibilidade ao trabalho desenvolvido pelos enfermeiros auditores internos do HCE. Tal visibilidade pode ser útil para a análise dos fluxos internos das contas hospitalares, revisão, aprimoramento e melhoria contínua das atividades a fim de agregar maior agilidade e resolutividade aos processos; para padronizar os procedimentos desenvolvidos e, consequentemente, evitar/minimizar a ocorrência de falhas e para subsidiar a elaboração de indicadores gerenciais, pois uma vez que estes processos estão descritos e acessíveis contribuem para que os profissionais otimizem o tempo despendido e obtenham melhores resultados.

Ao mapear, descrever e validar o processo de formação de contas em um hospital público universitário, de nível terciário, especializado em cardiologia e pneumologia, estudo ${ }^{(5)}$ demonstrou que os resultados obtidos permitiram a proposição de estratégias para minimizar o tempo de apresentação das contas às OPS, além de conferir visibilidade à dinâmica do processo, considerado fundamental para o equilíbrio econômico-financeiro do hospital. Foi explicitada a importância de partilhar o conhecimento 
obtido, tornando-o domínio público e acessível, uma vez que outras organizações de saúde poderiam utilizar as informações geradas para incrementar o seu faturamento e diminuir as divergências entre o prontuário do paciente e a conta hospitalar ${ }^{(5)}$.

Estudo sobre mapeamento de processos em uma farmácia hospitalar demonstrou que quando o colaborador passa a entender melhor suas tarefas, e o impacto que estas têm para o macroprocesso, a sua produtividade aumenta ocorrendo melhoria contínua da qualidade ${ }^{(11)}$.

É fundamental iniciar o redesenho dos processos a partir da responsabilidade de cada um, dos possíveis limites e interfaces das atividades, avaliando quem são os clientes, fornecedores e seus desempenhos, quais atividades agregam valor e geram retrabalho e, então, introduzir as melhorias no desempenho dos processos analisados. Trata-se de, para além de apenas controlar os resultados, desenvolver, entre os colaboradores, a percepção de que os processos se inter-relacionam, sendo preciso ouvir, favorecer a capacitação e a integração das pessoas envolvidas ${ }^{(12)}$.

O mapeamento de processos confere a capacidade de reação mais ágil às mudanças, internas e externas, uma vez que proporciona o controle e monitoramento das ações empreendidas. Possibilita, ainda, visualizar a existência de algum ponto crítico que possa comprometer o desempenho de todo o sistema organizacional. E, dessa forma, focalizar esforços conjuntos a fim de corrigi-los ou mesmo eliminá-los, evitando custos desnecessários e atrasos nos resultados ${ }^{(13)}$.

Por fim, constatada a escassez de estudos na literatura sobre o mapeamento, descrição e validação de processos, torna-se necessária a realização de novas investigações visando ampliar e verticalizar o conhecimento sobre a temática em questão.

\section{CONCLUSÃO}

O mapeamento, a descrição detalhada e a validação dos processos de auditoria e faturamento e de recurso de glosas, por especialistas da área de auditoria de contas hospitalares, conferem maior visibilidade e legitimidade às ações que são desenvolvidas pelos enfermeiros auditores e propiciam a rastreabilidade e a recuperação sistemática de informações com maior confiabilidade.

A metodologia adotada poderá ser reproduzida, em diferentes contextos hospitalares que invistam na auditoria interna de contas, para a realização de outros estudos que explicitem esses processos e, consequentemente, favoreçam o incremento contínuo do faturamento assistencial minimizando as perdas financeiras.

\section{REFERÊNCIAS}

1. Voese SB, Mello RJG. Análise bibliométrica sobre gestão estratégica de custos no Congresso Brasileiro de Custos: Aplicação da Lei de Lotka. Revista Capital Científico - Eletrônica (RCCe) [Internet]. 2013 [acesso em: 29 nov. 2017];11(1):1-19. Disponível em: http://revistas.unicentro.br/index.php/capitalcientifico/article/view/1995. 
2. Viana CD, Bragas LZT, Lazzari DD, Garcia CTF, Moura GMSS. Implementation of concurrent nursing audit: an experience report. Texto Context - Enferm [Internet]. 2016 [acesso em: 29 nov. 2017];25(1): e3250014. Disponível em: http://doi.org/10.1590/0104-070720160003250014.

3. Tronchin DMR, Freitas GF, Melleiro MM. Avaliação de Serviços, qualidade e segurança do paciente no Setor Saúde. In: Kurcgant P. Gerenciamento em enfermagem. 3a ed. Rio de Janeiro: Guanabara Koogan, 2016. p. 59-73.

4. Mauriz C, Lobo F, Lima RR, Oliveira S, Medeiros G. Faturamento hospitalar: um passo a mais. Revista Inovação Ação [Internet]. 2012 [acesso em: 29 nov. 2017];1(1):38-44. Disponível em:

http://www4.fsanet.com.br/revista/index.php/inovaacao/article/view/479/pdf.

5. Guerrer GFF, Castilho V, Lima AFC. Processo de formação de contas em um hospital de ensino especializado em cardiologia e pneumonia. Rev. Eletr. Enf. [Internet]. 2014 [acesso em: 29 nov. 2017];16(3):558-65. Disponível em: http://doi.org/10.5216/ree.v16i3.23487.

6. Dorne J, Hungare JV. Conhecimentos teóricos de auditoria em enfermagem. Revista UNINGÁ Review [Internet]. 2013 [acesso em: 29 nov. 2017];15(1):11-7. Disponível em:

https://www.mastereditora.com.br/periodico/20130723 000516.pdf.

7. Yin RK. Estudo de caso: Planejamento e método. 5a ed. Porto Alegre: Bookman; 2015.

8. Guerrer GFF, Lima AFC, Castilho V. Estudo da auditoria de contas em um hospital de ensino. Rev Bras Enferm [Internet]. 2015 [acesso em: 29 nov. 2017];68(3):414-20. Disponível em: http://doi.org/10.1590/00347167.2015680306i.

9. Miyashita PT, Salomn VAP. Mapeamento de processos em empresa prestadora de serviços de seguros. In: XXXI Encontro Nacional de Engenharia de Produção, 2011, Belo Horizonte, Brasil [Internet]. 2011 [acesso em: 29 nov. 2017]. Disponível em: http://www.abepro.org.br/biblioteca/enegep2011_TN_STP $135 \quad 855$ 17627.pdf.

10. Alvarenga THP, Piekarski CM, Santos BS, Bittencourt JVM, Matos EASA, Francisco AC. Aspectos relevantes sobre mapeamento de processos. Revista de Engenharia e Tecnologia. 2013;5(2):87-98.

11. Meiners MMMA, Figueiredo ACB, Areda CA, Galato D, Carvalho DSB. Mapeamento de processos em uma farmácia hospitalar: ferramenta para gestão e melhoria da qualidade. Revista Brasileira de Farmácia Hospitalar e Serviços de Saúde [Internet]. 2015 [acesso em: 29 nov. 2017];6(3):27-33. Disponível em:

http://www.sbrafh.org.br/rbfhss/index/edicoes/vl/6/nr/3/id/808/lg/0.

12. Demarchi TM. Gestão por processos como ferramenta da qualidade em um hospital-maternidade público do município de São Paulo. RAS. Revista de administração em saúde [Internet]. 2012 [acesso em: 29 nov.

2017];14(54):37-43. Disponível em:

http://www.cqh.org.br/portal/pag/anexos/baixar.php?p_ndoc=267\&p_nanexo=297.

13. Rocha TAH, Rodrigues JM, Silva NC, Barbosa ACQ. Gestão de recursos humanos em saúde e mapeamento de processos-reorientação de práticas para promoção de resultados clínicos satisfatórios. Revista de Administração Hospitalar [Internet]. 2014 [acesso em: 29 nov. 2017];11(3):143-59. Disponível em:

http://doi.org/10.21450/rahis.v11i3.2075. 